\title{
Effect of Early Weaning and Prolonged Nursing on Development of the Rat Pancreas
}

\author{
P.C. LEE, O.K. KIM, AND EMANUEL LEBENTHAL ${ }^{(15)}$ \\ Division of Gastroenterology and Nutrition, Children's Hospital of Buffalo, Buffalo, New York, USA
}

\begin{abstract}
Summary
Pancreatic development was studied in rats 17-28 days of age. Control pups, weaned naturally at 21-24 days showed a gradual increase in body weight, pancreatic weight, total DNA and protein content with age. Pups weaned at 17 days showed a transient increase in pancreatic weight and protein content only at day 22; at no time did they show a difference in either DNA content or body weight. Pups nursed up to 25 days of age had a smaller body weight, but had DNA and protein content similar to control rats. Control pups showed gradual increases in lipase and trypsinogen with a sharp increase in amylase between days 22 and 25. Pups weaned at 17 days showed a precocious increase in trypsinogen and a sharp increase in amylase between days 19-22, but an immediate decrease in lipase which eventually returned to the control level at day 28. Pups nursed beyond the weaning stage showed an increase in lipase and trypsinogen but no sharp increase in amylase. A significant increase in all pancreatic enzymes, pancreatic mass, pancreatic DNA and protein content was seen in all groups of rats irrespective of their diet. The results suggest an inherent biological program as a basic control of pancreatic ontogeny with diet playing a modifying role.
\end{abstract}

\section{Speculation}

Significant increases in pancreatic hydrolases occur with weaning. The laboratory chow used for weaning is low in fat and high in carbohydrate in contrast to milk which is high in fat and low in carbohydrate. Increases in some pancreatic hydrolases are dependent on the dietary transition. Early weaning will prematurely induce and prolonged nursing will delay the increase of these enzymes.

Postnatal development of pancreatic exocrine enzymes has been studied extensively in rats. The activities of amylase, trypsinogen and lipase remain relatively low before day 17 . Rapid accumulation of these enzymes occur at days 20-25, reaching a level 10-20 times that found before weaning $(5,13)$.

Increases in pancreatic hydrolases during the weaning period may be preprogrammed and/or be the result of dietary changes associated with weaning. The diet of the pup characteristically changes from a high lipid mother's milk to a high carbohydrate laboratory chow. Compositions of diets have been shown to regulate levels of pancreatic hydrolases in postweaning and adult rats $(4,5,9,12)$. The contribution of dietary changes to pancreatic enzyme development at the preweaning and weaning period has been studied only to a limited extent. Suckling rats, undergoing prolonged nursing, failed to show an increase in amylase but did show an increase in chymotrypsinogen (13). This may be indirectly related to a change of diet. Another study showed that weaning rats whose mothers were fed high starch diets had higher amylase levels; however, compared to pups of mothers fed high fat diets, they had lower trypsinogen and chymotrypsinogen levels and an unchanged lipase concentration up to day 25 (5). It was surmized that amylase and trypsinogen had already responded to dietary changes before weaning. Lipase, on the other hand, was not affected by diet before 25 days of age. The effect of diet in this case was, however, indirect. It was presumably related to changes in the composition of the mothers' milk. Because these compositions were not evaluated, the relationship between diet and pancreatic enzyme development of the suckling rat cannot be assessed.

This report examines the effect of dietary changes, by early weaning and prolonged nursing, on suckling rats. Specifically, it evaluates the contribution of dietary versus inherently programmed changes on the development of the exocrine pancreas during the critical period of weaning.

\section{MATERIALS AND METHODS}

Animals. Pregnant Sprague-Dawley rats were housed on the 15th day of gestation in individual cages with a $12 \mathrm{~h}$ light-dark cycle. The day of birth was considered day 0 . At day 1 , all pups were removed, pooled, and redistributed such that each mother had 12 pups. Each mother with her group of pups was housed separately. They were fed laboratory chow (Wayne Lab Blox, Allied Mills, Inc., Chicago, IL) and water ad libitum until day 17 when experiments began.

Procedures. At day 17, pups were removed, pooled and separated into three groups. In group 1, "control weaning," mothers and pups were allowed to stay together with access to lab chow and water throughout the experiment. In group 2, "forced weaning," mothers were removed and pups were fed powdered chow during the next three days followed by regular chow pellets thereafter. In group 3, "prolonged nursing," pups were prevented from access to lab chow. Two sets of mothers were used. One set of mothers was allowed to feed in a separate cage while the second set of mothers was nursing. The two sets of mothers were switched every $6 \mathrm{~h}$ for alternate feeding and nursing.

Preparation of pancreatic homogenate. At 17, 19, 22 and 25 days of age, three to five rats from each group were killed. For groups 1 and 2, experiments were carried out further to 28 days. The whole pancreas was removed and trimmed of fat and mesentery. After tissue wet weight was determined, the whole pancreas was minced in 10 volumes of ice cold water. Tissue preparations were then homogenized with a Potter-Elvehjem homogenizer using a motor driven teflon pestle for $30 \mathrm{sec}$ with the vessel immersed in crushed ice. The homogenate was then sonicated for $5 \mathrm{sec}$. Single homogenates were used for the determination of trypsinogen, amylase, lipase, DNA and protein.

Biochemical determinations. Protein was determined by the technique of Lowry (8) using bovine serum albumin fraction $\mathrm{V}$ as the standard. DNA was precipitated by cadmium chloride and measured by the colorimetric reaction with diphenylamine reagent according to Burton (2) using highly polymerized calf thymus DNA as the standard.

Trypsinogen was first activated with enterokinase, at a constant ratio of enterokinase/homogenate proteins, for $45 \mathrm{~min}$ at $25^{\circ} \mathrm{C}$; these conditions yielded optimal and reproducible activation of this zymogen in our laboratory. The enterokinase used was partially purified from mucosa of the proximal small intestine of rats 
following the procedure of Baratti et al. (1) up to the acidification step. Trypsin activity was then measured from the hydrolysis of $p$ nitroaniline from the substrate benzoyl-DL-arginine $p$-nitroaniline (BAPNA) at pH 8.2 and $25^{\circ} \mathrm{C} \mathrm{(6).} \mathrm{Units} \mathrm{are} \mathrm{expressed} \mathrm{as} \mathrm{nmoles}$ of BAPNA hydrolyzed per min per $\mathrm{mg}$ protein. Lipase activity was determined by potentiometric titration (at a constant $\mathrm{pH} \mathrm{8)}$ of ionized fatty acids liberated from an olive oil emulsion (11). Units are expressed as $\mu$ moles of $\mathrm{NaOH}$, which was required to neutralize the free fatty acid liberated per min per mg of protein. Amylase was determined by the saccharogenic method (10) using soluble starch as the substrate. Units are expressed as $\mu$ moles of maltose liberated per min per mg protein.

Statistics. All results are presented as mean \pm S.E. Differences between means of two groups were evaluated by unpaired Student's $t$ test with $P<0.05$ considered as significant.

\section{RESULTS}

Table 1 summarizes the developmental changes in body weight, pancreatic weight, total pancreatic contents of protein and DNA. Forced weaning did not affect body growth. Prolonged nursing, however, led to a slight decrease in body weight. Early weaning promoted growth of the pancreas, which reached a mass substantially greater than that of controls by day 22 . Prolonged nursing led to a slight increase in pancreatic mass at day 19; at 25 days, the pancreas became significantly smaller than that of the control or forced weaned litter mates. Total protein in the pancreas, in general, reflected the changes in the pancreatic mass. Early weaning or prolonged nursing did not change the DNA content at any of the ages studied.

Both early weaning and prolonged nursing affected the content and concentrations of selected enzymes in the developing rat pancreas (Fig. 1 and 2). Early weaning led to a transient, greater increase in the trypsinogen content at 22 days of age (Fig. 1A). Prolonged nursing also caused an increase in pancreatic content of trypsinogen as early as 19 days, and persisted to 22 days of age (Fig. 1A). At 25 days, no difference in trypsinogen content among the three groups was detected (Fig. 1A).

In the control rats, a slight increase of amylase content over the 17 day level was detected by day 19 (Fig. 1B). A significant increase was demonstrated at day 25 . Early weaning slightly increased the pancreatic content of amylase over the control by day 19. A dramatic increase over the control level was evident only at day 22 . At 19 and 22 days, the development of the amylase in the prolonged nursing group paralleled that of the controls and showed a significant increase over the 17-day-old level. At 25 days, when the control rats showed a sharp increase in amylase, prolonged nursing resulted in only a moderate increase (Fig. 1B).

Early weaning led to a significant reduction in lipase content as early as 19 days (Fig. 1C). These low levels were maintained through 25 days of age. Even at 28 days a slightly lower lipase content compared to controls could still be seen. In contrast, prolonged nursing led to greatly increased lipase content. This was seen at 19,22 , and 25 days of age.

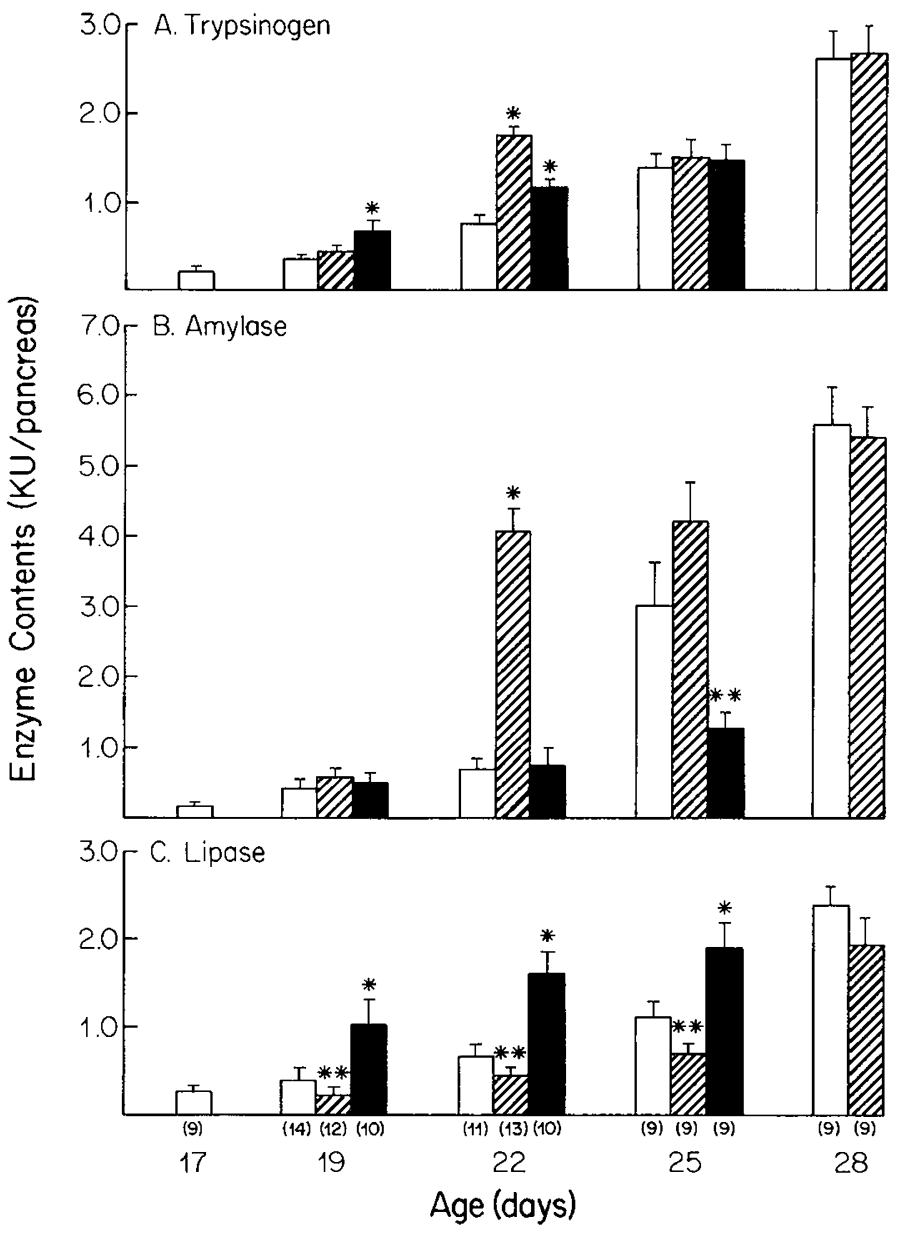

Fig. 1. Effect of forced weaning and preventing weaning in the developmental changes of trypsinogen, amylase and lipase contents in pancreases of weaning rats. Height of bar represents the mean of results from all animals from the same age and group. Open bar, control; shaded bar, early weaning; and solid bar, preventing weaning. Lines on top of bars represent S.E. Numerals in bracket on the $y$ axis denote numbers of animals used for the experiment. ${ }^{*}$ Values significantly higher than control values. ${ }^{* *}$ Values significantly lower than control values $(P<0.05)$.

Table 1. Effect of early weaning and preventing weaning on the developmental changes in body weight, pancreas weight, total protein and DNA content in pancreases of weaning rats ${ }^{1}$

\begin{tabular}{|c|c|c|c|c|c|c|}
\hline Age (days after birth) & 17 & & 19 & 22 & 25 & 28 \\
\hline \multirow[t]{3}{*}{ Body wt (gm) } & $31.5 \pm 0.7(9)$ & group 1 & $34.2 \pm 1.4(14)$ & $44.7 \pm 2.0(11)$ & $56.4 \pm 1.7(9)$ & $72.5 \pm 3.4(9)$ \\
\hline & & group 2 & $33.6 \pm 1.1(12)$ & $45.0 \pm 1.5(13)$ & $58.2 \pm 1.0(9)$ & $71.3 \pm 2.4(9)$ \\
\hline & & group 3 & $33.0 \pm 3.5(10)$ & $38.2 \pm 4.1(10)$ & $44.1 \pm 0.9^{2}(9)$ & \\
\hline \multirow[t]{3}{*}{ Pancreas wt (mg) } & $123 \pm 11$ & group 1 & $169 \pm 16$ & $241 \pm 23$ & $325 \pm 21$ & $414 \pm 17$ \\
\hline & & group 2 & $163 \pm 17$ & $338 \pm 22^{2}$ & $320 \pm 12$ & $398 \pm 9$ \\
\hline & & group 3 & $180 \pm 13$ & $252 \pm 16$ & $260 \pm 10^{2}$ & \\
\hline \multirow{3}{*}{$\begin{array}{l}\text { Total protein per pancreas } \\
(\mathrm{mg})\end{array}$} & $12.4 \pm 0.8$ & group 1 & $18.9 \pm 1.1$ & $28.2 \pm 2.4$ & $41.3 \pm 2.4$ & $54.8 \pm 3.7$ \\
\hline & & group 2 & $20.8 \pm 0.9$ & $44.6 \pm 2.5^{2}$ & $44.0 \pm 2.5$ & $52.0 \pm 3.9$ \\
\hline & & group 3 & $24.0 \pm 1.9^{2}$ & $32.5 \pm 3.7$ & $37.4 \pm 2.2$ & \\
\hline \multirow{3}{*}{$\begin{array}{l}\text { Total DNA per pancreas } \\
\text { (mg) }\end{array}$} & $1.11 \pm 0.18$ & group 1 & $1.50 \pm 0.11$ & $2.20 \pm 0.15$ & $3.10 \pm 0.13$ & $3.80 \pm 0.20$ \\
\hline & & group 2 & $1.65 \pm 0.15$ & $2.34 \pm 0.17$ & $3.02 \pm 0.20$ & $3.65 \pm 0.17$ \\
\hline & & group 3 & $1.50 \pm 0.17$ & $2.30 \pm 0.07$ & $3.00 \pm 0.17$ & \\
\hline
\end{tabular}

\footnotetext{
${ }^{1}$ Values represent the mean \pm S.E. of all animals in the same age and group. Numerals in brackets denote the number of rats used for the experiment.
} Group 1, control; Group 2, early weaning; and Group $3=$ preventing weaning.

${ }^{2}$ Values significantly different from control $(P<0.05)$. 
The pancreatic concentrations of trypsinogen, amylase, and lipase also changed during the weaning period (Fig. 2). In control animals, trypsinogen increased gradually and reached the adult level by day 28 . Early weaning led to a transient increase in trypsinogen specific activity at day 22 . Prolonged nursing, however, resulted in a sustained increase in trypsinogen specific activity starting at day 19 (Fig. 2A).

The amylase specific activity in control animals increased gradually from days 17-22 (Fig. 2B). A sharp increase was seen at day 25 , reaching the adult level by day 28 . Early weaning led to a premature increase in amylase to near adult levels at day 22. Prolonged nursing, prevented the sharp increase at day 25 . In spite of the comparatively lower concentrations, the amylase was still significantly increased over that found at 17 days.

Early weaning immediately depressed the lipase concentrations, only to return to the control level at day 25 . Prolonged nursing caused an increase in lipase specific activity (Fig. 2C).

\section{DISCUSSION}

Postnatal development of the rat pancreas is marked by significant changes around day 17 , when rapid increases in mass, DNA and enzyme content occurs. Because these changes coincide with the time of weaning, they may be a result of a dietary shift or inherent programming. In order to evaluate these factors, we have examined the effect of early weaning and prolonged nursing on the development of the pancreas in 17-28-day-old rat pups. Our

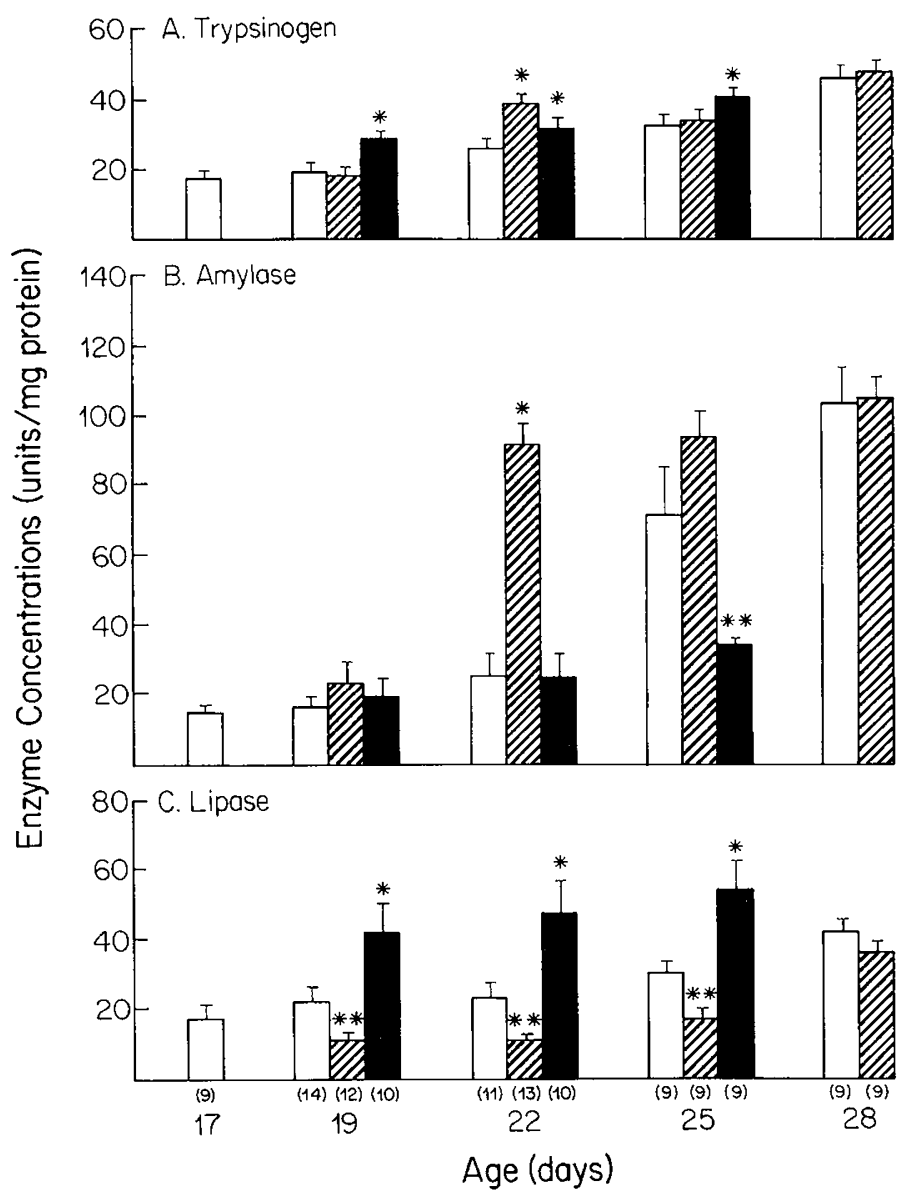

Fig. 2. Effect of forced weaning and preventing weaning on the developmental changes in pancreatic concentrations of trypsinogen, amylase and lipase in weaning rats. Height of bar represents the mean of results from all animals from the same age group. Open bar, control; shaded bar, early weaning; and solid bar, preventing weaning. Lines on top of bars represent S.E. Numerals in bracket on the $y$ axis denote numbers of animals used for the experiment. * Values significantly higher than control values. ** Values significantly lower than control values $(P<0.05)$.
Table 2. Comparison of rat milk and laboratory chow compositions

\begin{tabular}{lcc}
\hline \multicolumn{1}{c}{$\begin{array}{c}\text { Major } \\
\text { ingredients }\end{array}$} & $\begin{array}{c}\text { Rat milk } \\
\text { (Ref. no. 3) } \\
(\mathrm{g} \%)\end{array}$ & $\begin{array}{c}\text { Laboratory } \\
\text { chow } \\
(\mathrm{g} \%)\end{array}$ \\
\hline Protein & 11.8 & 24.0 \\
Fat & 14.8 & 4.0 \\
Carbohydrate & 2.8 & 50.0 \\
Fiber & & 4.5 \\
\hline
\end{tabular}

results indicate that a strong relationship exists between genetic programming and dietary influences on the development of the pancreatic enzymes amylase, trypsinogen, and lipase.

Rat milk has a high fat, low carbohydrate content. In comparison, the laboratory chow used for weaning has a high carbohydrate, low fat content (Table 2). It also has twice the amount of protein of rat's milk. Early weaning changes the nutrient consumption abruptly from a high fat, low carbohydrate diet to a low fat, high carbohydrate diet. Prolonged nursing, on the other hand, prolongs the consumption of a high fat, low carbohydrate diet. Changes observed in the pancreas of rats undergoing prolonged nursing can be due to inherent programming whereas changes noted in early weaned rats can be attributed to dietary influence which may be nutritional or hormonal.

Our results showed that early weaning did not affect the general growth of the rat (Table 1). As observed previously (7, 13), prolonged nursing led to retarded growth, which is more likely related to the restricted supply of nutrients in general rather than to the fat to carbohydrate ratios in the diet. Other possibilities include alterations in the composition of the milk, the feeding behavior of the sucklings, and possible hormonal changes.

Early weaning had a dramatic effect on the development of the pancreas leading to a rapid increase in pancreatic mass at day 22 compared to that of controls. This increase in mass is not due to increases in the number of cells since the DNA content is identical in the controls, but rather increases in general cell size as demonstrated by the increase in total protein content. After the 22nd day, the rate of pancreatic growth slows down considerably. At 25 days it becomes indistinguishable from the control rats. A fairly linear rate of growth is maintained by the control rats which presumably results from a more gradual transition of milk to laboratory chow during the same developmental period. An important observation is that although prolonged nursing limits the pancreatic mass, the DNA content at 25 days is normal. Dietary changes are not, therefore, required for pancreatic cell division but rather for stimulation of the somatic growth of the pancreas.

Dietary changes had significant effects on the development of pancreatic trypsinogen, amylase and lipase in weaning rats. Our results indicate a precocious induction of trypsinogen and amylase with a corresponding depression of lipase after early weaning. The increase in amylase and decrease in lipase can be attributed to the consumption of a high carbohydrate, low fat laboratory chow. The increase in trypsinogen is more complicated to explain, because prolonged nursing also led to an increase. The increase in trypsinogen therefore is not related to the higher protein content of the laboratory chow.

The significant increase in lipase in rats undergoing prolonged nursing and the sharp decrease in lipase in early weaned rats at day 19, suggest the importance of lipids in influencing the development of pancreatic lipases. The rat pancreas seems to adapt to dietary changes after day 17 so that a high fat milk diet led to induction of lipase, and a low fat chow diet to a depression in lipase. A similar increase in lipase has also been observed by Snook (13) in rats without access to mother's food.

The continual increase of amylase in rats undergoing prolonged nursing suggests an inherently programmed increase in this enzyme irrespective of the diet. The contribution of the genetic preprogramming in controlling pancreatic development is also illustrated by the parallel increase in its DNA content despite the 
dietary variations. In addition, both lipase and trypsinogen show a developmental increase in which superimposed dietary influences either increase, as in lipase of the prolonged nursing rats, or decrease as in lipase of the forced weaned rat. There is therefore a definite control of pancreatic development by the genetic preprogramming in rats. Dietary changes, in turn, may modify the temporal sequence of events in the natural progression of pancreatic ontogeny. This is evidenced by the precocious induction of amylase and pancreatic growth in early weaned rats but eventually results in a pancreas of weight, protein, DNA and enzyme contents similar to that of the control weaned rats during subsequent development.

\section{REFERENCES AND NOTES}

1. Baratti, J., Maroux, S., Louvard, D., and Desnuelle, P.: On porcine enterokinase Further purification and some molecular properties. Biochim. Biophys. Acta, 315: 147 (1973)

2. Burton, K.: A study of the conditions and mechanism of the diphenylamine reaction for the colorimetric estimation of deoxyribonucleic acid. Biochem. J., 62: 315 (1956).

3. Cox, W. M., Jr. and Mueller, A. J.: Composition of milk from stock rats and apparatus for milking small laboratory animals. J. Nutr., 13: 249 (1937).

4. Deschodt-Lanckman, M., Robberecht, P., Camus, J., and Christophe, J.: Short term adaptation of pancreatic hydrolases to nutritional and physiological stimuli in adult rats. Biochimie, 53: 789 (1971)

5. Deschodt-Lanckman, M., Robberecht, P., Camus, J., Baya, C., and Christophe J.: Hormonal and dietary adaptation of rat pancreatic hydrolases before and after weaning. Am. J. Physiol., 226: 39 (1974).

6. Erlanger, D. F., Kokowski, N., and Cohen, W.: The preparation and properties of two new chromogenic substrate of trypsin. Arch. Biochem. Biophys. 95: 271 (1961).

7. Lebenthal, E., Sunshine, P., and Kretchmer, N.: Effect of prolonged nursing on the activity of intestinal lactase in rats. Gastroenterology, 64: 1136 (1973).

8. Lowry, O. H., Rosebrough, N. J., Farr, A. L., and Randall, R. J.: Protein measurement with the Folin phenol reagent. J. Biol. Chem., 193: 265 (1951).

9. Robberecht, P., Deschodt-Lanckman, M., Camus, J., Bruylands, J., and Christophe, J.: Rat pancreatic hydrolases from birth to weaning and dietary adaptation after weaning. Am. J. Physiol., 221: 376 (1971)

10. Searcy, R. L., Hayashi, S., and Berk, J. E.: A new microsaccharogenic method for serum amylase determination. Tech. Bull. Regist. Med. Tech., 36: 252 (1966).

11. Smeriva, M., DuFour, P., and Desnuelle, P.: On the probable involvement of a histidine residue in the active site of pancreatic lipase. Biochemistry, 10:1214 (1971).

12. Snook, J. T.: Dietary regulation of pancreatic enzyme synthesis. Secretion and inactivation in the rat. J. Nutr., 87: 297 (1965).

13. Snook. J. T.: Effect of diet on development of exocrine pancreas of the neonatal rat. Am. J. Physiol., 221: 1388 (1971).

14. The authors thank S. Brooks, B. Krantz, and S. Kohut for their skillful technical assistance and Mrs. M. Arseneau and Dr. L. Heitlinger for their help in the preparation of the manuscript.

15. Requests for reprints should be addressed to: Dr. E. Lebenthal, Division of Gastroenterology and Nutrition, Children's Hospital of Buffalo, 219 Bryant St., Buffalo, NY 14222.

16. This research was supported in part by National Institute of Health Grant \#12586 and National Science Foundation Grant \#PCM-8021817.

17. Received for publication August 19, 1981.

18. Accepted for publication November 9, 1981. 